\title{
Randomised, double-blind, placebo-controlled study of olanzapine in patients with bipolar I depression*
}

Mauricio Tohen, David P. McDonnell, Michael Case, Shigenobu Kanba, Kyooseob Ha, Yi Ru Fang, Hideaki Katagiri and Juan-Carlos Gomez

\section{Background}

Atypical antipsychotics are widely used in bipolar mania. However, the efficacy of atypical antipsychotics in bipolar depression has not been comprehensively explored.

\section{Aims}

To evaluate olanzapine monotherapy in patients with bipolar depression.

\section{Method}

Patients with bipolar depression received olanzapine (5-20 mg/day, $n=343)$ or placebo $(n=171)$ for 6 weeks. The primary outcome was change from baseline to end-point in Montgomery-Åsberg Depression Rating Scale (MADRS) total score. Secondary outcomes included: Clinical Global Impression - Bipolar Version (CGI-BP) scale, 17-item Hamilton Rating Scale for Depression (HRSD-17) and Young Mania Rating Scale (YMRS) scores, and the rate of response $(\geqslant 50 \%$ reduction in MADRS at end-point), recovery (MADRS $\leqslant 12$ for $\geqslant 4$ weeks plus treatment completion) and remission (MADRS $\leqslant 8$ ). The trial was registered with ClinicalTrials.gov (NCT00510146).

\section{Results}

Olanzapine demonstrated: significantly greater $(P<0.04)$ improvements on MADRS (least-squares mean change -13.82 v. -11.67), HRSD-17 and YMRS total scores and all CGI-BP subscale scores $V$. placebo; significantly $(P \leqslant 0.05)$ more response and remission, but not recovery; significantly $(P<0.01)$ greater mean increases in weight, fasting cholesterol and triglycerides; and significantly more $(P<0.001)$ patients gained $\geqslant 7 \%$ body weight.

\section{Conclusions}

Olanzapine monotherapy appears to be efficacious in bipolar depression. Additional long-term studies are warranted to confirm these results. Safety findings were consistent with the known safety profile of olanzapine.

\section{Declaration of interests}

D.P.M., H.K., J-C.G. and M.C. are full-time employees and minor stockholders of Eli Lilly and Company. M.T. was an employee of Eli Lilly and Company while the study was conducted (until 2008) and has received honoraria from or consulted for AstraZeneca, Bristol-Myers Squibb,

GlaxoSmithKline, Eli Lilly and Company, Johnson \& Johnson, Sepracor, Otsuka, Merck, Sunovion, Forest, Lundbeck, Roche, Wyeth and Wiley Publishing; his spouse is a current employee and minor stockholder at Eli Lilly and Company. S.K. received grants and research support from GlaxoSmithKline, Pfizer, Yoshitomi, Kyowa-Hakko, Astellas, Meiji and Otsuka; was a consultant for Eli Lilly and Company, GlaxoSmithKline, Pfizer, Ono, Asahi-Kasei, Shionogi and Otsuka; and received honoraria from Eli Lilly and Company, GlaxoSmithKline, Pfizer, Janssen, Meiji, Kyowa-Hakko, Dainippon-Sumitomo, Otsuka, Eisai, Taisho-Toyama and Astellas. K.H. has received grants, research support and honoraria from Pfizer, Otsuka, Astrazeneca and Eli Lilly and company.
Bipolar disorder is a chronic, progressive disease that presents severe challenges for long-term treatment because each episode seems to increase the risk for another episode, and subsequent episodes appear to be increasingly treatment resistant. ${ }^{1}$ Pharmacological treatment options are limited, and mounting evidence suggests that exposure to antidepressants increases long-term mood instability in patients with bipolar disorder. ${ }^{2,3}$ Considering those challenges, novel treatment options are needed and are being investigated. A limited number of clinical trials have explored the use of atypical antipsychotics to treat depression in bipolar disorder. Quetiapine demonstrated efficacy when used as monotherapy for treatment of bipolar depression in two placebo-controlled trials of patients with bipolar I or bipolar II disorder experiencing a major depressive episode. ${ }^{4,5}$ In three placebo-controlled clinical trials, aripiprazole did not show efficacy in the treatment of acute bipolar depression or in the prevention of depressive relapse. ${ }^{6,7}$ Similarly, a placebocontrolled trial of ziprasidone did not show efficacy for the

*Aspects of this study have been presented at the 9th International Conference on Bipolar Disorder (Pittsburgh, Pennsylvania, USA, 9-11 June 2011). treatment of depression in patients with bipolar I disorder. ${ }^{8}$ The efficacy and safety of a second-generation atypical antipsychotic, olanzapine, and the combination of olanzapine and fluoxetine in the treatment of depressive episodes in patients with bipolar disorder were examined in a single-protocol study that was divided into two identical, 8-week studies. Analyses of the whole sample showed that both olanzapine and combination therapy with olanzapine and fluoxetine were significantly more effective than placebo. ${ }^{9}$ However, when the two identical studies were analysed separately, the olanzapine/fluoxetine combination remained significantly more effective than placebo in both studies, but olanzapine alone was significantly more effective than placebo in only one study (details available from the author on request). Significantly more patients in the olanzapine and olanzapine/ fluoxetine groups reported somnolence, weight gain, increased appetite, dry mouth and asthaenia compared with the placebo group $(P \leqslant 0.03) .{ }^{9}$ These treatment-emergent adverse events are similar to those observed during treatment with olanzapine/ fluoxetine combination in a 6-month study comparing olanzapine/fluoxetine combination with lamotrigine in patients with bipolar I disorder depression ${ }^{10}$ as well as those seen during 
a 24-week open-label extension study comparing olanzapine/ fluoxetine combination and olanzapine monotherapy in the treatment of bipolar depression. ${ }^{11}$

The current study was intended to evaluate whether olanzapine is superior to placebo in the treatment of patients with diagnosed bipolar I disorder with an acute major depressive episode. In addition, we aimed to examine the extent to which these findings can be applied to a primarily East Asian population.

\section{Method}

The primary objective of the current study was to assess whether olanzapine $(5-20 \mathrm{mg} /$ day) is superior to placebo in patients with bipolar I disorder depression on the basis of symptom improvement as measured by the least-squares mean baseline to end-point change in Montgomery-Åsberg Depression Rating Scale (MADRS) ${ }^{12}$ total score. Secondary objectives were to assess additional measures of efficacy across the range of bipolar mood states and to examine rates of response, remission, recovery and study discontinuation and the emergence of mania. The safety of olanzapine treatment in this population was also assessed through evaluation of treatment-emergent adverse events; changes in vital signs, laboratory analytes and electrocardiograms (ECGs); emergence of suicidality or serious suicidal risk; and the incidence and severity of extrapyramidal symptoms.

The protocol was reviewed and approved by the appropriate institutional review boards before study initiation. The study was conducted in conformity with the USA Food and Drug Administration Code of Federal Regulations (21 CFR, Part 50), and the Declaration of Helsinki and its amendments. Study procedures and execution were consistent with Good Clinical Practice guidelines and all applicable regulatory requirements. The trial was registered with ClinicalTrials.gov (NCT00510146).

\section{Patients}

Male and female patients aged $\geqslant 18$ years and $<65$ years who met diagnostic criteria for bipolar I disorder and a major depressive episode as defined by DSM-IV-TR ${ }^{13}$ were recruited. Patients were required to have been in a depressive episode for $\leqslant 90$ days at the time of randomisation, to have a 17-item Hamilton Rating Scale for Depression (HRSD-17) $)^{14}$ total score $\geqslant 18$ and to have a history of $\geqslant 1$ manic or mixed episode in the previous 6 years without currently being in a manic episode (Young Mania Rating Scale $(\text { YMRS })^{15}$ total score $<8$ at randomisation). Excluded were patients with an unstable medical illness (where death was anticipated within 1 year, or intensive care unit hospitalisation for the disease was anticipated within 6 months of screening); a history of diabetes or a haemoglobin $A_{1 c} \geqslant 6.5 \%$ or blood glucose level indicative of diabetes; recent substance dependence; a history of serious psychiatric illness other than bipolar disorder; recent use of clozapine, depot antipsychotics or central nervous system medications other than mood stabilisers; and current rapidcycling mood disturbance. Patients were recruited in Japan, China, Taiwan, Korea and the USA in both in-patient and out-patient settings. After complete description of the study to the patients, written informed consent was obtained.

\section{Study design}

This was a 6-week, randomised, double-blind, placebo-controlled, phase 3 trial of olanzapine as monotherapy for treatment of patients with bipolar disorder in a depressive state. A screening visit occurred 2-28 days before the double-blind acute treatment to determine patient eligibility. Patients who met all inclusion criteria and no exclusion criteria were enrolled in the study and randomly assigned in a 2:1 ratio to olanzapine and placebo once daily at bedtime. Patients were stratified by region and randomised at the study level. Assignment to treatment groups was determined by a computer-generated random sequence using an interactive voice response system. The response system was used to assign blister packs containing double-blind study drug to each patient. Patient numbers were assigned at visit 1 , and patients who met all criteria for enrollment were randomly allocated to double-blind treatment at visit 2 by the interactive voice response system.

Starting at visit 2, patients assigned to the olanzapine group received the study drug $5 \mathrm{mg}$ /day once daily; after 3-7 days (visit 3 or 4 ) at this dose, patients underwent a forced titration to $10 \mathrm{mg} /$ day olanzapine once daily. On the basis of the investigator's judgement, the single daily olanzapine dose could be increased to $20 \mathrm{mg}$ or decreased to $5 \mathrm{mg}$ at subsequent once-weekly study visits.

\section{Efficacy evaluation}

Efficacy of the study medication was evaluated with changes from baseline to 6 weeks on the MADRS total score; the Clinical Global Impression - Bipolar Version (CGI-BP) ${ }^{16}$ including the depression, mania and bipolar subscale scores; the HRSD-17 total score; and the YMRS total score. Post hoc analysed were MADRS item-by-item scores and the MADRS- 6 subscale, which focuses on the 'core' symptoms of depression (as assessed by the MADRS items: Apparent Sadness, Reported Sadness, Inner Tension, Lassitude, Inability to Feel, and Pessimistic Thoughts). ${ }^{17,18}$ Response was defined as a $\geqslant 50 \%$ reduction in MADRS at end-point. Remission was a priori defined as a MADRS total score $\leqslant 12$ (called partial remission in this paper) and was defined post hoc as a MADRS total score $\leqslant 8$ (as recommended by the International Society for Bipolar Disorders, ${ }^{19}$ called full remission in this paper). Recovery assessment was based on a MADRS total score $\leqslant 12$ for $\geqslant 4$ weeks of treatment and completion of the 6-week acute phase.

\section{Safety evaluation}

To assess the safety of the study medication, spontaneously reported treatment-emergent adverse events were collected at every visit. Laboratory analytes and ECGs were assessed at baseline and at end-point, with clinical chemistry, lipid panel, electrolyte and hematology measures also being collected at visit 5 . Vital signs and weight were assessed at each study visit. Additionally, the Drug-Induced Extrapyramidal Symptoms Scale (DIEPSS) ${ }^{20}$ and the Mini International Neuropsychiatric Interview (MINI) ${ }^{21}$ to assess suicidality were administered at every study visit.

\section{Statistical analysis}

Calculations determined that a total of 510 patients (olanzapine, $n=340$; placebo, $n=170$ ) would have $90 \%$ power (type II error $=0.1$ ) to detect a treatment difference of 3.9 of MADRS total score change from baseline. Because this study included patients from geographical regions in which olanzapine in bipolar depression has not been studied, a conservative standard deviation of 12.38 was used; this corresponds to an effect size of 0.315 . The sample size for each treatment group was based on the use of a two-sided $t$-test of significance, with alpha (type I error) $=0.05$.

All analyses were based on the intention-to-treat set of patients. All tests of treatment effect were conducted at a twosided significance level of 0.05 , and no adjustments for multiple comparisons were made. Continuous data were assessed using 
analysis of covariance models with type III sums of squares with terms for treatment and geographical region and with the baseline measurement value included as a covariate. For continuous data where a baseline measurement was not applicable, analysis of variance models were used, with terms for treatment and geographical region. The primary analysis of change from baseline to end-point in MADRS total score was based on last observation carried forward (LOCF) least-squares mean change. Additionally, observed case visit-wise analyses and mixed-effects repeated measures analysis of variance were used to assess changes in MADRS total score. For analysis of proportions, the CochranMantel-Haenszel test was used to adjust for geographical region in efficacy assessments; the Fisher exact test was used when geographical region was not adjusted, mainly for safety assessments. Times to discontinuation, to response and to remission were evaluated using the log rank test from Kaplan-Meier survival analyses.

\section{Results}

\section{Patient disposition}

The first patient enrolled into the study on 27 August 2007, and the last patient completed the study on 9 July 2010. A total of 514 patients were randomly assigned to treatment. The acute phase of the study was completed by 267 of the 343 patients assigned to the olanzapine group $(77.8 \%)$ and by 122 of the 171 patients in the placebo group $(71.3 \% ; P=0.126)$ (Fig. 1). A total of 30 patients receiving olanzapine $(8.7 \%)$ and 13 patients receiving placebo $(7.6 \%)$ discontinued $(P=0.737)$ because of adverse events.

\section{Baseline demographics}

Treatment groups were similar in gender, ethnicity, age, age at onset of bipolar disorder and history of prior depressive, manic and mixed episodes as well as illness severity demonstrated by baseline MADRS total, HRSD-17 total, and YMRS total scores, and CGI-BP mania, depression and bipolar subscales (Table 1).

\section{Primary efficacy outcome}

The baseline to end-point decrease (improvement) in leastsquares mean MADRS total score was significantly greater in the olanzapine group than in the placebo group after 6 weeks of double-blind treatment $(-13.82 v .-11.67 ; P=0.018)$, with an effect size of 0.22 . At all study visits, except at week 1 , the olanzapine group had significantly greater reductions in leastsquares mean MADRS total score than the placebo group (LOCF analysis, Fig. 2). Sensitivity analyses using observed case (week 2: -11.10 v. $-9.17, P=0.007$; week 6: -15.61 v. $-13.02, P=0.006$ ) and mixed-effects repeated measures (week 2: -11.05 v. -9.26 , $P=0.013$; week 6: -15.65 v. $-13.02, P=0.007)$ methodologies yielded similar results. Baseline to end-point score changes on individual MADRS items and the MADRS-6 subscale are presented in Table 2 (LOCF and mixed-effects repeated measures analyses).

\section{Secondary efficacy outcomes}

The olanzapine group had a greater baseline to end-point improvement in CGI-BP depression, CGI-BP mania and CGI-BP bipolar subscales scores, as well as the HRSD-17 total score, compared with the placebo group (Fig. 3 and Table 3). Patients demonstrated a low level of mania symptoms at baseline (mean YMRS 2.08 (s.d.=2.13)), and patients treated with olanzapine had statistically greater least-squares mean decreases from baseline to end-point in YMRS total score compared with patients treated with placebo (Table 3 and online Fig. DS1).

Patients in the olanzapine group had significantly higher rates of response than those treated with placebo $(P=0.0498)$ (Table 4 and online Fig. DS2). In addition, Kaplan-Meier survival analysis showed a significant difference $(P=0.038)$ between treatment group curves, with an estimate of median time to response for the olanzapine group of 32 days $v .45$ days in the placebo group. Partial remission rates for the olanzapine group and the placebo group did not differ significantly $(P=0.367)$ when remission was defined $a$ priori as MADRS total score $\leqslant 12$ (Table 4 and Fig. DS2). However, when remission was defined post hoc as

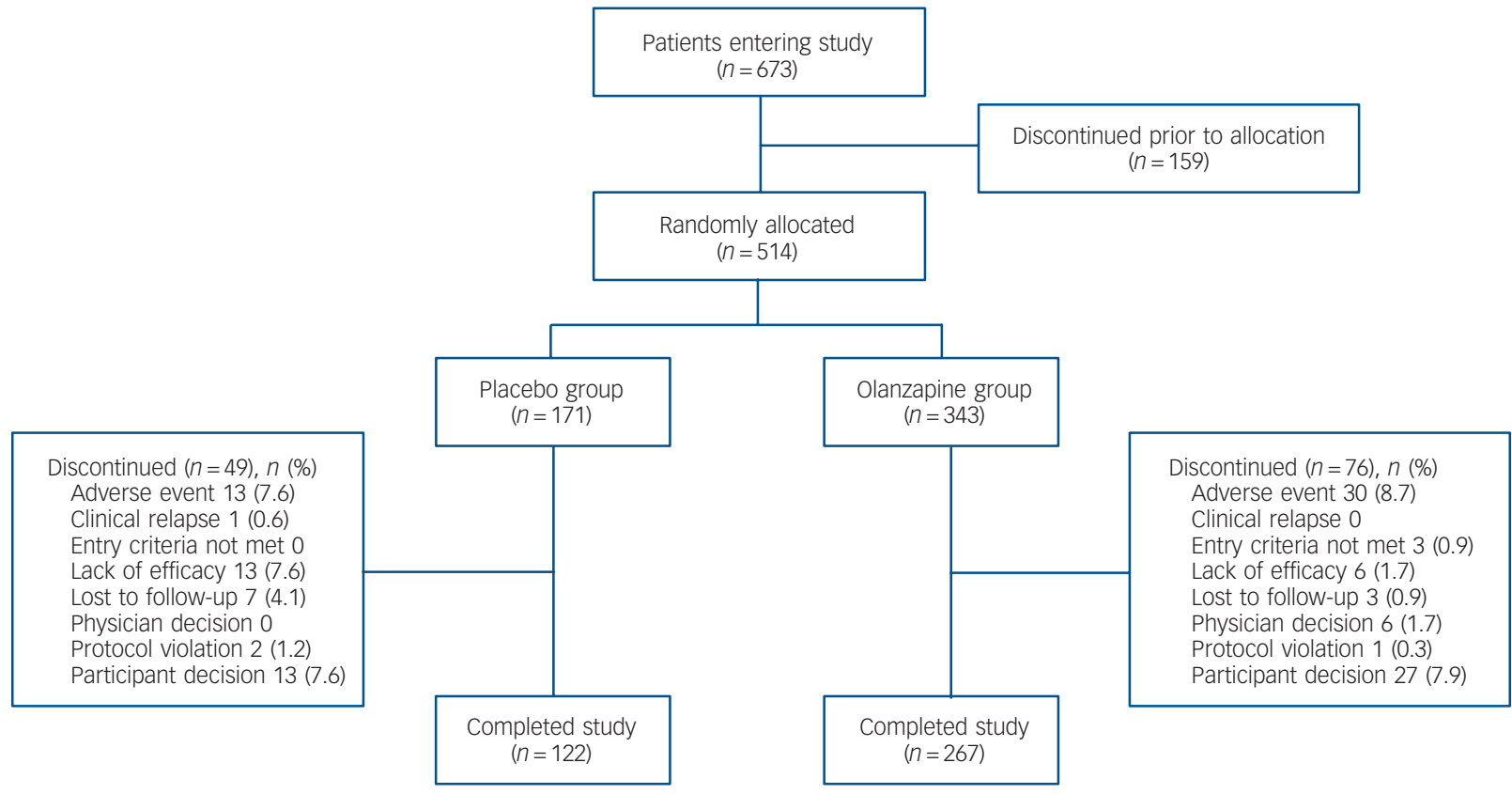

Fig. 1 Flow diagram of patient disposition during the acute phase. 


\begin{tabular}{|c|c|c|c|c|}
\hline \multirow[b]{2}{*}{ Female, $n(\%)$} & \multicolumn{2}{|c|}{ Placebo $(n=171)$} & \multicolumn{2}{|c|}{ Olanzapine $(n=343)$} \\
\hline & 95 & 55.6 & 205 & 59.8 \\
\hline \multicolumn{5}{|l|}{ Ethnicity, $n(\%)$} \\
\hline White & 22 & 12.9 & 36 & 10.5 \\
\hline African & 4 & 2.3 & 18 & 5.2 \\
\hline Hispanic & 3 & 1.8 & 6 & 1.7 \\
\hline East Asian & 141 & 82.5 & 282 & 82.2 \\
\hline Native American & 1 & 0.6 & 1 & 0.3 \\
\hline Age, years: mean (s.d.) & 35.0 & 11.0 & 36.0 & 11.1 \\
\hline Age at onset of bipolar disorder, years: mean (s.d.) & 26.1 & 9.9 & 27.6 & 11.0 \\
\hline \multicolumn{5}{|l|}{ Prior episodes, mean (s.d.) } \\
\hline Manic & 3.6 & 4.1 & 3.4 & 4.8 \\
\hline Depressive & 5.3 & 9.0 & 5.0 & 7.8 \\
\hline Mixed & 0.9 & 2.6 & 0.8 & 4.7 \\
\hline \multicolumn{5}{|l|}{ Illness severity scores, mean (s.d.) } \\
\hline MADRS total & 28.7 & 6.3 & 29.3 & 5.7 \\
\hline YMRS total & 2.0 & 2.2 & 2.1 & 2.1 \\
\hline HRSD-17 total & 22.3 & 3.5 & 22.6 & 3.5 \\
\hline CGI-BP depression & 4.5 & 0.7 & 4.5 & 0.7 \\
\hline CGI-BP bipolar & 4.4 & 0.8 & 4.5 & 0.8 \\
\hline CGI-BP mania & 1.1 & 0.3 & 1.1 & 0.3 \\
\hline
\end{tabular}

MADRS total score $\leqslant 8$, significantly more olanzapine-treated patients went into remission compared with those receiving placebo $(P=0.038)$ (Table 4 and Fig. DS2). No significant between-group differences were observed for recovery $(P=0.156)$ (Table 4$)$.

\section{Safety results}

Overall, safety data from the acute phase of this study were consistent with the known safety profile of olanzapine. Significantly more patients in the olanzapine group $(n=239,69.7 \%)$ experienced $\geqslant 1$ treatment-emergent adverse events compared with patients in the placebo group $(n=93,54.4 \% ; P<0.001)$. The most commonly reported adverse events for olanzapine-treated patients were somnolence, increased weight, increased appetite and sedation (online Table DS1). Using the American Diabetes Association criteria to assess abnormal blood glucose levels (www.diabetes.org/ diabetes-basics/prevention/pre-diabetes/diagnosis.html) and the National Cholesterol Education Program criteria ${ }^{22}$ to assess lipid changes, we identified categorical changes with potential clinical significance occurring more often in the olanzapine group than in the placebo group (online Table DS2). Compared with patients in the placebo group, a higher percentage of the olanzapine group experienced a categorical shift in fasting cholesterol from normal to borderline $(P<0.001)$ and from borderline to high $(P=0.005)$, in fasting triglycerides from normal to high $(P=0.022)$, and in fasting glucose from impaired to high $(P=0.048)$ and from normal/impaired to high $(P=0.019)$ (Table DS2). The percentages of patients experiencing categorical shifts in fasting low-density lipoprotien from normal to borderline, normal to high, and borderline to high, and in fasting high-density lipoprotein from normal to low were not significantly different between treatment groups (Table DS2). After 6 weeks of treatment, patients in the olanzapine group had significantly greater weight gain than patients in the placebo group $(P<0.001)$ (online Table DS3), and weight gain $\geqslant 7 \%$ above baseline occurred more commonly in the olanzapine group $(P<0.001)$ (Table DS2). Mean increases in fasting cholesterol $(P<0.001)$, low-density lipoprotien cholesterol $(P<0.001)$ and fasting triglycerides $(P=0.003)$ were also higher in the olanzapine group (Table DS3).
Regarding laboratory values other than glucose and lipids, a higher proportion of patients receiving olanzapine had treatmentemergent abnormal high values for alanine aminotransferase $(P<0.001)$, aspartate aminotransferase $(P<0.001)$, gamma-glutamyl transpeptidase $(P=0.005)$ and prolactin $(P<0.001)$ and abnormal low values for neutrophils $(P=0.012)$ compared with patients receiving placebo. A higher proportion of the placebo group had treatment-emergent abnormal high values for hematocrit $(P=0.033)$ and mean cell volume $(P=0.029)$ and treatmentemergent abnormal low values for potassium $(P<0.001)$ compared with the olanzapine group.

No significant differences between treatment groups were observed in the proportion of patients with potentially clinically significant changes in ECG intervals and heart rate. No between-group differences were observed in extrapyramidal symptoms measured through DIEPSS total score mean change from baseline to end-point, and no significant differences between

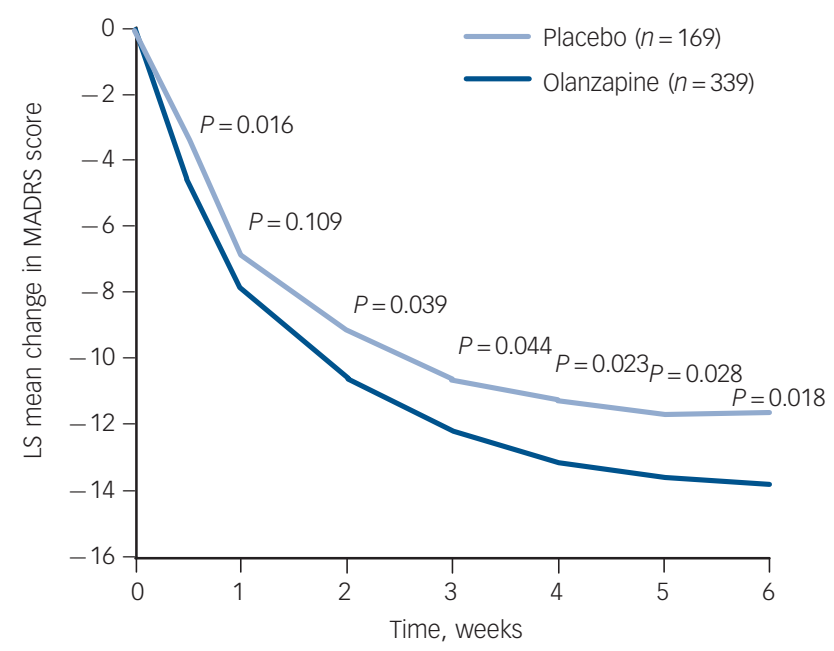

Fig. 2 Last observation carried forward analysis of visit-wise change from baseline in least-squares (LS) mean MontgomeryÅsberg Depression Rating Scale (MADRS) total score. 
Table 2 Baseline to end-point least-squares (LS) mean changes on individual MADRS items and MADRS-6 subscale

\begin{tabular}{|c|c|c|c|c|c|c|c|c|c|c|c|c|c|}
\hline \multirow[b]{3}{*}{ MADRS item } & \multirow[b]{3}{*}{ Group } & \multicolumn{7}{|c|}{ Last observation carried forward analysis } & \multicolumn{5}{|c|}{ Mixed model repeated measures analysis } \\
\hline & & \multirow[b]{2}{*}{$n$} & \multicolumn{2}{|c|}{ Baseline } & \multicolumn{2}{|c|}{ End-point } & \multicolumn{2}{|c|}{$P^{a}$} & \multirow[b]{2}{*}{$n$} & \multicolumn{2}{|c|}{ End-point } & \multicolumn{2}{|c|}{$P^{\mathrm{b}}$} \\
\hline & & & Mean & s.d. & $\begin{array}{l}\text { LS mean } \\
\text { change }\end{array}$ & s.e. & $\begin{array}{l}\text { Within } \\
\text { group }\end{array}$ & $\begin{array}{l}\text { Between } \\
\text { group }\end{array}$ & & $\begin{array}{l}\text { LS mean } \\
\text { change }\end{array}$ & s.e. & $\begin{array}{l}\text { Within } \\
\text { group }\end{array}$ & $\begin{array}{l}\text { Between } \\
\text { group }\end{array}$ \\
\hline \multirow[t]{2}{*}{ Apparent sadness } & PLB & 169 & 3.52 & 0.91 & -1.53 & 0.12 & $<0.001$ & 0.652 & 127 & -1.71 & 0.12 & $<0.001$ & 0.330 \\
\hline & OLZ & 339 & 3.57 & 0.96 & -1.59 & 0.09 & $<0.001$ & & 271 & -1.85 & 0.08 & $<0.001$ & \\
\hline \multirow[t]{2}{*}{ Reported sadness } & PLB & 169 & 3.55 & 0.97 & -1.54 & 0.12 & $<0.001$ & 0.183 & 127 & -1.68 & 0.12 & $<0.001$ & 0.021 \\
\hline & OLZ & 339 & 3.73 & 0.91 & -1.71 & 0.09 & $<0.001$ & & 271 & -1.99 & 0.08 & $<0.001$ & \\
\hline \multirow[t]{2}{*}{ Inner tension } & PLB & 169 & 2.82 & 1.11 & -0.85 & 0.11 & $<0.001$ & 0.005 & 127 & -0.96 & 0.11 & $<0.001$ & $<0.001$ \\
\hline & OLZ & 339 & 2.83 & 0.97 & -1.17 & 0.08 & $<0.001$ & & 271 & -1.37 & 0.08 & $<0.001$ & \\
\hline \multirow[t]{2}{*}{ Reduced sleep } & PLB & 169 & 3.20 & 1.42 & -1.35 & 0.13 & $<0.001$ & $<0.001$ & 127 & -1.62 & 0.13 & $<0.001$ & $<0.001$ \\
\hline & OLZ & 339 & 3.32 & 1.52 & -2.05 & 0.10 & $<0.001$ & & 271 & -2.29 & 0.09 & $<0.001$ & \\
\hline \multirow[t]{2}{*}{ Reduced appetite } & PLB & 169 & 2.02 & 1.53 & -1.04 & 0.10 & $<0.001$ & $<0.001$ & 127 & -1.21 & 0.09 & $<0.001$ & $<0.001$ \\
\hline & OLZ & 339 & 1.99 & 1.47 & -1.46 & 0.08 & $<0.001$ & & 271 & -1.60 & 0.07 & $<0.001$ & \\
\hline \multirow{2}{*}{$\begin{array}{l}\text { Concentration } \\
\text { difficulties }\end{array}$} & PLB & 169 & 3.41 & 1.04 & -1.10 & 0.12 & $<0.001$ & 0.347 & 127 & -1.30 & 0.12 & $<0.001$ & 0.346 \\
\hline & OLZ & 339 & 3.37 & 0.95 & -1.22 & 0.09 & $<0.001$ & & 271 & -1.42 & 0.08 & $<0.001$ & \\
\hline \multirow[t]{2}{*}{ Lassitude } & PLB & 169 & 3.17 & 1.10 & -1.38 & 0.11 & $<0.001$ & 0.752 & 127 & -1.42 & 0.12 & $<0.001$ & 0.603 \\
\hline & OLZ & 339 & 3.28 & 1.06 & -1.41 & 0.09 & $<0.001$ & & 271 & -1.49 & 0.08 & $<0.001$ & \\
\hline \multirow[t]{2}{*}{ Inability to feel } & PLB & 169 & 3.34 & 1.06 & -1.45 & 0.12 & $<0.001$ & 0.426 & 127 & -1.56 & 0.12 & $<0.001$ & 0.219 \\
\hline & OLZ & 339 & 3.49 & 0.98 & -1.56 & 0.09 & $<0.001$ & & 271 & -1.73 & 0.09 & $<0.001$ & \\
\hline \multirow{2}{*}{$\begin{array}{l}\text { Pessimistic } \\
\text { thoughts }\end{array}$} & PLB & 169 & 2.53 & 1.12 & -1.04 & 0.11 & $<0.001$ & 0.085 & 127 & -1.06 & 0.11 & $<0.001$ & 0.007 \\
\hline & OLZ & 339 & 2.68 & 1.05 & -1.24 & 0.08 & $<0.001$ & & 271 & -1.41 & 0.08 & $<0.001$ & \\
\hline \multirow[t]{2}{*}{ Suicidal thoughts } & PLB & 169 & 1.14 & 0.95 & -0.44 & 0.08 & $<0.001$ & 0.806 & 127 & -0.54 & 0.07 & $<0.001$ & 0.794 \\
\hline & OLZ & 339 & 1.11 & 0.99 & -0.42 & 0.06 & $<0.001$ & & 271 & -0.52 & 0.05 & $<0.001$ & \\
\hline \multirow{2}{*}{$\begin{array}{l}\text { MADRS-6 } \\
\text { subscale }\end{array}$} & PLB & 169 & 18.93 & 4.12 & -7.74 & 0.58 & $<0.001$ & 0.133 & 127 & -8.35 & 0.57 & $<0.001$ & 0.030 \\
\hline & OLZ & 339 & 19.58 & 3.75 & -8.68 & 0.45 & $<0.001$ & & 271 & -9.82 & 0.41 & $<0.001$ & \\
\hline \multicolumn{14}{|c|}{$\begin{array}{l}\text { MADRS, Montgomery-Åsberg Depression Rating Scale; OLZ, olanzapine; PLB, placebo. } \\
\text { a. Within group P-values are from } t \text {-tests on LS mean change; } P \text {-values and LS mean for change from baseline are from analysis of covariance model: change =treatment + } \\
\text { baseline + geographic region (Type III sums of squares). } \\
\text { b. Within group } P \text {-values are from } t \text {-tests on LS mean change; } P \text {-values are from Type III sums of squares and Kenward-Roger approximation as denominator degrees of freedom; } \\
\text { MMRM analysis: change = treatment + baseline + geographic region + visit + treatment * visit. } \\
\text { C. MADRS-6 subscale contains six individual MADRS items: Apparent Sadness, Reported Sadness, Inner Tension, Lassitude, Inability to Feel, and Pessimistic Thoughts, considered } \\
\text { to be 'core' depressive symptoms. }{ }^{12,13}\end{array}$} \\
\hline
\end{tabular}

the groups were detected for changes from baseline to end-point in suicidality total scores.

\section{Discussion}

\section{Main findings}

Results presented here are consistent with those from a prior study in which olanzapine monotherapy proved superior to placebo in reducing depressive symptoms in patients with bipolar disorder experiencing an acute depressive episode. ${ }^{9}$ Here, we used a study population largely of East Asian ethnicity, whereas the previous study examined a largely non-Asian population. ${ }^{9}$

Improvements in depressive symptoms were noted using multiple assessment tools (MADRS, HRSD-17 and CGI-BP) and criteria for response. These assessment tools are well established in the literature and frequently used in clinical practice to examine depressive symptoms in a variety of patient populations. ${ }^{23-25}$ Improvement of core symptoms of depression as assessed by the MADRS-6 subscale (containing the following MADRS items: Apparent Sadness, Reported Sadness, Inner Tension, Lassitude, Inability to Feel, and Pessimistic Thoughts) was significantly greater during treatment with olanzapine compared with placebo when analysed with mixed-effects repeated measures; baseline to end-point changes on the MADRS-6 subscale were numerically, but not statistically significantly $(P=0.133)$ greater during treatment with olanzapine compared with placebo when analysed with LOCF. These results suggest that olanzapine has an effect on the core symptoms of depression.

The effect size demonstrated by olanzapine monotherapy in this study was modest. Although this could be a sign of a modest effect of the active drug treatment, it may also have been influenced by a relatively high response to placebo. Increasing placebo response in recent years is a phenomenon which has been shown in different areas of psychopharmacology. ${ }^{26,27}$ Nevertheless, the consistency of the results across different assessment tools, as well as response rate and the post hoc remission rate (no significant

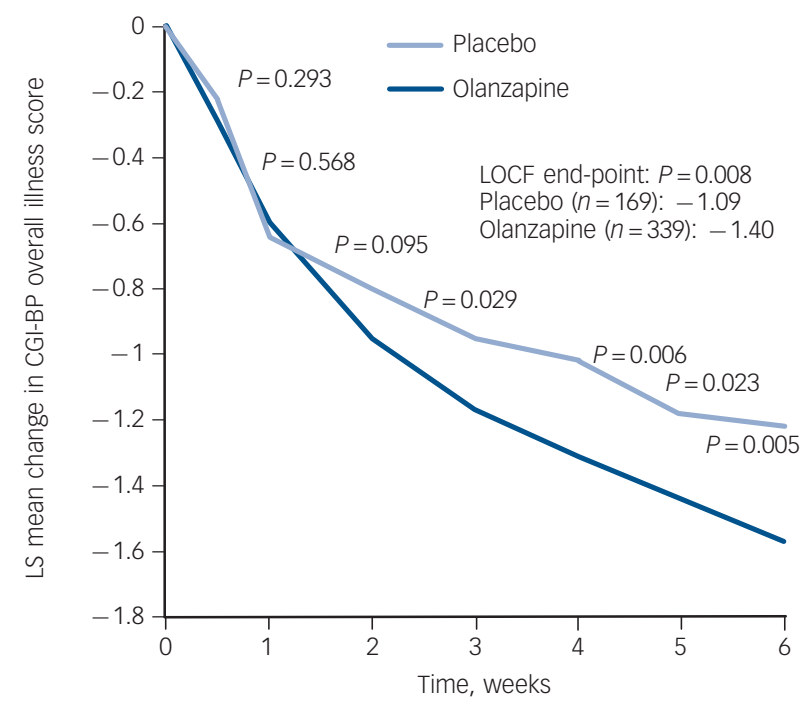

Fig. 3 Observed case analysis of visit-wise change from baseline in least-squares (LS) mean Clinical Global Impression - Bipolar Version (CGI-BP) overall illness score. LOCF, last observation carried forward. 
Table 3 Baseline to end-point least-squares mean changes on CGI-BP, HRSD-17 and YMRS

\begin{tabular}{|c|c|c|c|c|c|}
\hline & \multicolumn{2}{|c|}{ Placebo $(n=169)$} & \multicolumn{2}{|c|}{ Olanzapine $(n=339)$} & \multirow[b]{2}{*}{$P$} \\
\hline & Least squares mean & s.e. & Least squares mean & s.e. & \\
\hline CGI-BP mania & 0.10 & 0.04 & -0.01 & 0.03 & 0.008 \\
\hline CGI-BP depression & -1.19 & 0.11 & -1.43 & 0.08 & 0.037 \\
\hline CGI-BP bipolar & -1.09 & 0.11 & -1.40 & 0.08 & 0.008 \\
\hline HRSD-17 total & -8.84 & $0.66^{\mathrm{a}}$ & -11.05 & $0.51^{b}$ & 0.002 \\
\hline YMRS total & 0.32 & 0.27 & -0.67 & 0.21 & $<0.001$ \\
\hline
\end{tabular}

Table 4 Response, remission and recovery rates

\begin{tabular}{|c|c|c|c|c|c|}
\hline & \multicolumn{2}{|c|}{ Placebo $(n=171)$} & \multicolumn{2}{|c|}{ Olanzapine $(n=343)$} & \multirow[b]{2}{*}{$P$} \\
\hline & Affected patients, $n$ & $\%$ & Affected patients, $n$ & $\%$ & \\
\hline Response & 74 & 43.3 & 180 & 52.5 & 0.0498 \\
\hline Partial remission & 85 & 49.7 & 185 & 53.9 & 0.367 \\
\hline Remission & 50 & 29.2 & 132 & 38.5 & 0.038 \\
\hline Recovery & 16 & 9.4 & 47 & 13.7 & 0.156 \\
\hline
\end{tabular}

between-group differences were observed for recovery and a priori remission rates), suggest that it is a clinically meaningful effect. It is important to consider that bipolar disorder is a particularly difficult to treat condition and that there are very few regulatory approved treatments for bipolar depression. Therefore, even a modest effect size may be of clinical relevance to patients, although treatment-emergent adverse events need to be taken into consideration as well. Future studies are warranted to explore long-term effectiveness and safety of olanzapine monotherapy in patients with bipolar depression. This seems to be especially important considering recent findings that indicate that early improvement in patients with bipolar disorder does not seem to be a reliable predictor of response or remission, while the absence of early improvement appears to be a highly reliable predictor of non-response. ${ }^{28,29}$ Additional potential limitations for long-term efficacy lie in the observation that a significant number of patients discontinue olanzapine owing to adverse events ${ }^{30}$ and that olanzapine, like other second-generation antipsychotics, is frequently not used at the recommended dose levels in patients with bipolar disorder. ${ }^{31}$

In the olanzapine group, no increase of manic symptoms occurred during our study, but YMRS scores improved. This finding has clinical implications because improvement of manic symptoms in patients with bipolar disorder has been shown to improve treatment outcomes. ${ }^{32}$ Additionally, this finding suggests that treatment of patients with bipolar disorder during a depressive episode with olanzapine monotherapy can produce a mood-stabilising effect without increasing the risk that the patient will cycle into a manic episode. Consistent with previous studies, patients treated with olanzapine had significantly $(P<0.01)$ greater mean increases in weight, fasting cholesterol and triglycerides compared with the placebo group, and a higher percentage of the olanzapine group experienced categorical shifts in fasting cholesterol, fasting triglycerides and fasting glucose. Additionally, significantly more $(P<0.001)$ patients receiving olanzapine gained $\geqslant 7 \%$ body weight. Overall, the safety profile of olanzapine during this 6-week trial was similar to that seen in previous studies of olanzapine therapy and consistent with the known safety profile of olanzapine treatment, indicating that olanzapine's safety profile in patients with bipolar disorder appears to be consistent across populations with different ethnicities.

\section{Limitations}

The interpretation of the data is limited by the fact that the remission analysis was post hoc; however, the criteria used in the remission analysis were very stringent and were recommended by the International Society for Bipolar Disorders. Additionally, our criteria used to define recovery (MADRS $\leqslant 12$ for $\geqslant 4$ weeks plus treatment completion) might have been too stringent considering the total study length was only 6 weeks. Finally, the results presented here are limited to: patients at least 18 years old and younger than 65 years; patients who had been in a depressive episode for $\leqslant 90$ days at the time of randomisation; patients without serious comorbid psychiatric illness; and patients who are not rapidly cycling. Future studies should consider including broader patient populations.

\section{Clinical implications}

In summary, olanzapine monotherapy has shown efficacy in the acute treatment of bipolar depression. Although the observed safety profile was similar to that seen during previous studies of olanzapine therapy, clinicians need to monitor safety carefully. In making treatment decisions for individual patients, clinicians should consider carefully the risks and benefits of olanzapine treatment for each individual patient.

Mauricio Tohen, MD, DrPH, MBA, University of Texas Health Science Center at San Antonio, San Antonio, Texas, USA; David P. McDonnell, MD; Michael Case, MSC, Lilly Research Laboratories, Eli Lilly and Company, Indianapolis, Indiana, USA; Shigenobu Kanba, MD, PhD, Kyushu University, Fukuoka, Japan and East Asian Bipolar Forum, Japan; Kyooseob Ha, MD, Seoul National University, Seoul, South Korea and East Asian Bipolar Forum, Japan; Yi Ru Fang, MD, PhD, Shanghai Jiao Tong University School of Medicine, Shanghai, China and East Asian Bipolar Forum, Tong University School of Medicine, Shanghai, China and East Asian Bipolar Forum,
Japan; Hideaki Katagiri, MD, PhD, Eli Lilly Japan K.K., Kobe, Japan; Juan-Carlos Gomez, MD, Lilly Research Laboratories, Eli Lilly and Company, Indianapolis, Indiana, USA

Correspondence: Mauricio Tohen, UT Health Science Center, Division of Mood and Anxiety Disorders, 7526 Louis Pasteur Drive, San Antonio, TX 78229-3900, USA. Email: tohen@uthscsa.edu

First received 3 Jan 2012, final revision 20 Jun 2012, accepted 27 Jun 2012 


\section{Funding}

This study was funded by Eli Lilly and Company.

\section{Acknowledgements}

The study findings presented here are derived from a collaboration of investigators in several Eastern Asian countries (China, Korea, Japan and Taiwan) with investigators in the USA to create a unique patient sample with predominantly East Asian ethnicity. This collaboration was the initiator that led to the formation of the East Asian Bipolar Forum (EABF; www.isbd.org/edcenter/chapters/affiliates.asp). The EABF contains experts in bipolar disorder from Korea, Japan, China and Taiwan, and aims to enhance international collaborations for improving treatments for bipolar disorders. The authors thank Dr Alexandra Heinloth and Ms Laura Altobelli, both full-time employees of PharmaNet/i3, part of inventiv Health Company, for assistance in the preparation of this manuscript.

\section{References}

1 McIntyre RS. Long-term treatment of bipolar disorder in adults. J Clin Psychiatry 2011; 72: e06.

2 Strejilevich SA, Martino DJ, Marengo E, Igoa A, Fassi G, Whitham EA, et al. Long-term worsening of bipolar disorder related with frequency of antidepressant exposure. Ann Clin Psychiatry 2011; 23: 186-92.

3 Ghaemi SN. Treatment of rapid-cycling bipolar disorder: are antidepressants mood destabilizers? Am J Psychiatry 2008; 165: 300-2.

4 Calabrese JR, Keck Jr PE, Macfadden W, Minkwitz M, Ketter TA, Weisler RH, et al. A randomized, double-blind, placebo-controlled trial of quetiapine in the treatment of bipolar I or II depression. Am J Psychiatry 2005; 162 1351-60.

5 Thase ME, Macfadden W, Weisler RH, Chang W, Paulsson B, Khan A, et al. Efficacy of quetiapine monotherapy in bipolar I and II depression: a doubleblind, placebo-controlled study (the BOLDER II study). J Clin Psychopharmacol 2006; 26: 600-9.

6 Quante A, Zeugmann S, Luborzewski A, Schommer N, Langosch J, Born C, et al. Aripiprazole as adjunct to a mood stabilizer and citalopram in bipolar depression: a randomized placebo-controlled pilot study. Hum Psychopharmacol 2010; 25: 126-32.

7 Thase ME, Jonas A, Khan A, Bowden CL, Wu X, McQuade RD, et al. Aripiprazole monotherapy in nonpsychotic bipolar I depression: results of 2 randomized, placebo-controlled studies. J Clin Psychopharmacol 2008; 28: 13-20.

8 Sachs GS, Ice KS, Chappell PB, Schwartz JH, Gurtovaya O, Vanderburg DG, et al. Efficacy and safety of adjunctive oral ziprasidone for acute treatment of depression in patients with bipolar I disorder: a randomized, double-blind, placebo-controlled trial. J Clin Psychiatry 2011; 72: 1413-22.

9 Tohen M, Vieta E, Calabrese J, Ketter TA, Sachs G, Bowden C, et al. Efficacy of olanzapine and olanzapine-fluoxetine combination in the treatment of bipolar I depression. Arch Gen Psychiatry 2003; 60: 1079-88.

10 Brown E, Dunner DL, McElroy SL, Keck PE, Adams DH, Degenhardt E, et al. Olanzapine/fluoxetine combination vs. lamotrigine in the 6-month treatmen of bipolar I depression. Int I Neuropsychopharmacol 2009; 12: 773-82.

11 Corya SA, Perlis RH, Keck Jr PE, Lin DY, Case MG, Williamson DJ, et al. A 24-week open-label extension study of olanzapine-fluoxetine combination and olanzapine monotherapy in the treatment of bipolar depression. J Clin Psychiatry 2006; 67: 798-806.

12 Montgomery SA, Åsberg M. A new depression scale designed to be sensitive to change. Br J Psychiatry 1979; 134: 382-9.

13 American Psychiatric Association. Diagnostic and Statistical Manual of Mental Disorders, Fourth Edition, Text Revision (DSM-IV-TR). APA, 2000.

14 Hamilton $M$. Development of a rating scale for primary depressive illness. Br J Clin Psychol 1967; 6: 278-96.
15 Young RC, Biggs JT, Ziegler VE, Meyer DA. A rating scale for mania: reliability, validity and sensitivity. Br J Psychiatry 1978; 133: 429-35.

16 Spearing MK, Post RM, Leverich GS, Brendt D, Nolan W. Modification of the Clinical Global Impressions (CGI) scale for use in bipolar illness (BP): the CGI-BP. Psychiatry Res 1997; 73: 159-71.

17 Thase ME, Bowden CL, Nashat M, Eudicone JM, Marcus R, McQuade RD, et al. Aripiprazole in bipolar depression: a pooled, post-hoc analysis by severity of core depressive symptoms. Int J Psychiatry Clin Pract 2012; 16: 121-31.

18 Bech P, Tanghoj P, Andersen HF, Overo K. Citalopram dose-response revisited using an alternative psychometric approach to evaluate clinical effects of four fixed citalopram doses compared to placebo in patients with major depression. Psychopharmacology (Berl) 2002; 163: 20-5.

19 Tohen M, Frank E, Bowden CL, Colom F, Ghaemi SN, Yatham LN, et al. The International Society for Bipolar Disorders (ISPD) Task Force report on the nomenclature of course and outcome in bipolar disorders. Bipolar Dis 2009; 11: $453-73$

20 Inada T. Evaluation and Diagnosis of Drug-induced Extrapyramidal Symptoms: Commentary on the DIEPSS and Guide to its Usage. Seiwa Shoten Publishers, 1996.

21 Sheehan DV, Lecrubier $Y$, Harnett-Sheehan $K$, Amorim $P$, Janavs J, Weiller $E$, et al. The Mini International Neuropsychiatric Interview (M.I.N.I.): the development and validation of a structured diagnostic psychiatric interview. J Clin Psychiatry 1998; 59 (suppl 20): 22-33.

22 National Cholesterol Education Program, National Heart, Lung, and Blood Institute, National Institutes of Health. Third Report of the National Cholesterol Education Program (NCEP) Expert Panel on Detection, Evaluation and Treatment of High Blood Cholesterol in Adults (Adult Treatment Panel III): Final Report. National Institutes of Health, 2002

23 Komossa K, Depping AM, Gaudchau A, Kissling W, Leucht S. Secondgeneration antipsychotics for major depressive disorder and dysthymia. Cochrane Database Syst Rev 2010; CD008121.

24 Gomeni R, Lavergne A, Merlo-Pich E. Modelling placebo response in depression trials using a longitudinal model with informative dropout. Eur J Pharm Sci 2009; 36: 4-10.

25 Vieta E, Blasco-Colmenares E, Figueira ML, Langosch JM, Moreno-Manzanaro $M$, Medina $E$, et al. Clinical management and burden of bipolar disorder: a multinational longitudinal study (WAVE-bd Study). BMC Psychiatry 2011; 11: 58

26 Kemp AS, Schooler NR, Kalali AH, Alphs L, Anand R, Awad G, et al. What is causing the reduced drug-placebo difference in recent schizophrenia clinical trials and what can be done about it? Schizophr Bull 2010; 36: 504-9.

27 Walsh BT, Seidman SN, Sysko R, Gould M. Placebo response in studies of major depression: variable, substantial, and growing. JAMA 2002; 287: $1840-7$

28 Kemp DE, Ganocy SJ, Brecher M, Carlson BX, Edwards S, Eudicone JM, et al. Clinical value of early partial symptomatic improvement in the prediction of response and remission during short-term treatment trials in 3369 subjects with bipolar I or II depression. J Affect Disord 2011; 130: 171-9.

29 Tohen M, Case M, Trivedi MH, Thase ME, Burke SJ, Durell TM. Olanzapine/ fluoxetine combination in patients with treatment-resistant depression: rapid onset of therapeutic response and its predictive value for subsequent overall response in a pooled analysis of 5 studies. J Clin Psychiatry 2010; 71: 451-62.

30 Gao K, Kemp DE, Fein E, Wang Z, Fang Y, Ganocy SJ, et al. Number needed to treat to harm for discontinuation due to adverse events in the treatment of bipolar depression, major depressive disorder, and generalized anxiety disorder with atypical antipsychotics. J Clin Psychiatry 2011; 72: 1063-71.

31 Rascati KL, Richards KM, Ott CA, Goddard AW, Stafkey-Mailey D, Alvir J, et al. Adherence, persistence of use, and costs associated with second-generation antipsychotics for bipolar disorder. Psychiatr Serv 2011; 62: 1032-40.

32 Benazzi F, Berk M, Frye MA, Wang W, Barraco A, Tohen M. Olanzapine/ fluoxetine combination for the treatment of mixed depression in bipolar I disorder: a post hoc analysis. J Clin Psychiatry 2009; 70: 1424-31. 